\title{
Factors Predictive of Adverse Events Associated with Endoscopic Ultrasound-Guided Fine Needle Aspiration of Pancreatic Solid Lesions
}

\author{
Akio Katanuma $\cdot$ Hiroyuki Maguchi $\cdot$ Kei Yane $\cdot$ Shunpei Hashigo $\cdot$ \\ Toshihumi Kin • Maki Kaneko - Shin Kato • Ryusuke Kato • Ryo Harada • \\ Manabu Osanai $\cdot$ Kuniyuki Takahashi $\cdot$ Masanori Nojima
}

Received: 29 October 2012 / Accepted: 24 January 2013/Published online: 20 February 2013

(C) The Author(s) 2013. This article is published with open access at Springerlink.com

\begin{abstract}
Background Endoscopic ultrasound-guided fine needle aspiration (EUS-FNA) provides high diagnostic accuracy with a low incidence of procedural complications. However, it occasionally causes serious complications, and factors that increase the susceptibility to such adverse events remain unknown.

Aims We aimed to examine post-procedural events and determine risk factors associated with EUS-FNA of pancreatic solid lesions.

Methods This single-center retrospective study included 316 consecutive patients with pancreatic solid lesions who underwent 327 EUS-FNA procedures from April 2003 to September 2011. We registered all patients undergoing EUS-FNA in the database and retrospectively ascertained the presence/absence of post-procedural adverse events.

Results The incidence of post-procedural adverse events, including moderate to mild pancreatitis, mild abdominal pain, and mild bleeding, was $3.4 \%$. Univariate analysis showed that the incidence of post-procedural events was significantly increased in patients with tumors less than or equal to $20 \mathrm{~mm}$ in diameter $(P<0.001)$, those with pancreatic neuroendocrine tumors (PNET) $(P=0.012)$, and patients who had intervening normal pancreas for accessing the lesion
\end{abstract}

A. Katanuma ( $\square) \cdot$ H. Maguchi · K. Yane $\cdot$ S. Hashigo ·

T. Kin · M. Kaneko - S. Kato - R. Kato - R. Harada .

M. Osanai · K. Takahashi

Center for Gastroenterology, Teine-Keijinkai Hospital,

1-40-1-12 Maeda, Teine-ku, Sapporo,

Hokkaido 006-8555, Japan

e-mail: akio-ka@ta2.so-net.ne.jp

M. Nojima

Department of Public Health, Sapporo Medical University

School of Medicine, Sapporo, Japan
$(P=0.048)$. Multivariate analysis identified tumors measuring less than or equal to $20 \mathrm{~mm}$ in diameter (OR 18.48; $95 \%$ CI 3.55-96.17) and case of PNETs (OR 36.50; $95 \%$ CI 1.73-771.83) were an independent risk factors.

Conclusions EUS-FNA of pancreatic solid lesions is a safe procedure. However, pancreatic lesions with small diameters and pancreatic neuroendocrine tumors are important factors associated with adverse events after EUS-FNA.

Keywords EUS-FNA - Adverse events - Pancreatitis · Risk factor · Pancreatic cancer $\cdot$ Pancreatic neuroendocrine tumor

\section{Introduction}

Endoscopic ultrasound-guided fine needle aspiration (EUSFNA) is a valuable tool for obtaining histological diagnoses and has been widely used since it was first reported [1]. EUS-FNA provides high histological diagnostic accuracy for pancreatic lesions, submucosal tumors, and lymph nodes [2-10]. Although adverse events such as pancreatitis, bleeding, and perforation are known to be associated with EUS-FNA, the reported complication rate is extremely low [11-16]. However, adverse events associated with EUSFNA have not yet been clearly defined and nor has their severity been classified. Moreover, the risk factors for adverse events associated with EUS-FNA procedures have not yet been determined. The purpose of this study was to determine the incidence of adverse events in patients undergoing EUS-FNA who were registered in our database and to identify risk factors for the development of postprocedural adverse events in patients who undergo FNA of pancreatic solid lesions. 


\section{Patients and Methods}

\section{Patients}

A total of 316 consecutive patients with pancreatic solid lesions who underwent 327 EUS-FNA procedures from April 2003 to September 2011 were included in the study (Table 1). We registered all patients undergoing EUS-FNA in the database and retrospectively ascertained the presence/absence of complications. We performed EUS-FNA on pancreatic solid lesions because cystic tumors were a contraindication at our center. Patients with hemorrhagic tendencies were not included as candidates for EUS-FNA, and those on anticoagulant therapy were instructed to discontinue the medication prior to the procedure. Prior to undergoing EUS-FNA, all patients provided written informed consent.

\section{EUS-FNA Procedures}

All patients who were scheduled to undergo FNA were hospitalized for the procedure. EUS-FNA procedures were performed by physicians who perform an average of 150 patients per year and have more than 10 years of experience. Blood analyses were performed less than $48 \mathrm{~h}$ before EUS-FNA. All the patients were placed in the left lateral position, and sedation was accomplished using either intravenous diazepam $(5 \mathrm{mg})$ or pethidine hydrochloride (35 mg) along with intravenous midazolam (5 mg). The

Table 1 Baseline characteristics of pts who underwent EUS-FNA of pancreatic solid lesions

\begin{tabular}{ll}
\hline Characteristics & Values \\
\hline Age, years, mean + SD (range) & $66.5 \pm 11.5(23-92)$ \\
Sex, M:F & $178: 149$ \\
Diagnosis & \\
Pancreatic cancer & $275(84.1 \%)$ \\
Chr. pancreatitis/TFP & $24(7.3 \%)$ \\
PNET & $13(4.0 \%)$ \\
AIP & $4(1.2 \%)$ \\
Metastatic tumor & $2(0.6 \%)$ \\
SPN & $2(0.6 \%)$ \\
Accessary spleen & $2(0.6 \%)$ \\
Others & $5(1.5 \%)$ \\
Needle size & \\
19-guage & $31(9.5 \%)$ \\
22-gauge & $268(82 \%)$ \\
25-gauge & $28(8.6 \%)$ \\
\hline
\end{tabular}

TFP tumor forming pancreatitis, PNET pancreatic neuroendocrine tumor, $A I P$ autoimmune pancreatitis, $S P N$ solid-pseudopapillary neoplasm patients were kept fasting after the procedure and given an antibiotic twice after the examination.

All FNA procedures were completed using a curved linear echo endoscope (GF-UCT240, GF-UCT260; Olympus Medical Systems, Tokyo, Japan). Basically, a 22-G needle (EZ-shot; Olympus Medical Systems; and EchoTip Ultra; Cook Medical, Winston-Salem, NC, USA) was used; however, a 19- or 25-G needle (EchoTip Ultra; Cook Medical) was selected when necessary. Immediately after the tissue samples were obtained, they were stained using the DiffQuik method in the presence of a cytologist to confirm the adequacy of the sample for cytological diagnosis.

All ultrasonography images obtained during the procedure were stored on a computer as electronic images. Using these images, we retrospectively confirmed whether the needle pass site as via normal pancreatic tissue (Fig. 1a, b). In cases where the needle pass was via normal pancreatic tissue, the length of the needle penetration was measured (Fig. 1c). The length was measured using a distance marker on the ultrasonography images and assigned to one of 3 categories: $<1,1-2$, and $>2 \mathrm{~cm}$.

\section{Assessment of Adverse Events and Variables}

Physicians and/or nurses confirmed the subjective symptoms and physical findings on the day following the procedure and at least 1 week later. Blood biochemical tests were also performed for all patients to detect any abnormalities in laboratory data. In patients with suspected complications, diagnostic imaging, including computed tomography (CT), was performed as needed. Adverse events and severity grading were defined according a report from a workshop held by the American Society for Gastrointestinal Endoscopy (ASGE) [17]. Acute pancreatitis was defined as upper abdominal pain associated with nausea or vomiting and accompanied by at least a threefold elevation of serum amylase or lipase. Significant gastrointestinal bleeding was defined as a drop in the hemoglobin level by $>2 \mathrm{~g} / \mathrm{dl}$ as compared with the preprocedure baseline levels together with clinical evidence of bleeding. Abdominal pain was defined as pain not caused by pancreatitis or perforation. Because all EUS-FNA procedures were performed in the hospitalized, the period until oral intake was used as a basis for evaluating severity instead of the length of hospital stay. Severity was classified as mild, moderate, or severe if the patient required less than 3 days of fasting, 4-10 days of fasting, or more than 10 days of fasting, respectively.

Statistical Analysis

Differences and linear trends in the proportions of the categorical variables were analyzed using Fisher's exact 

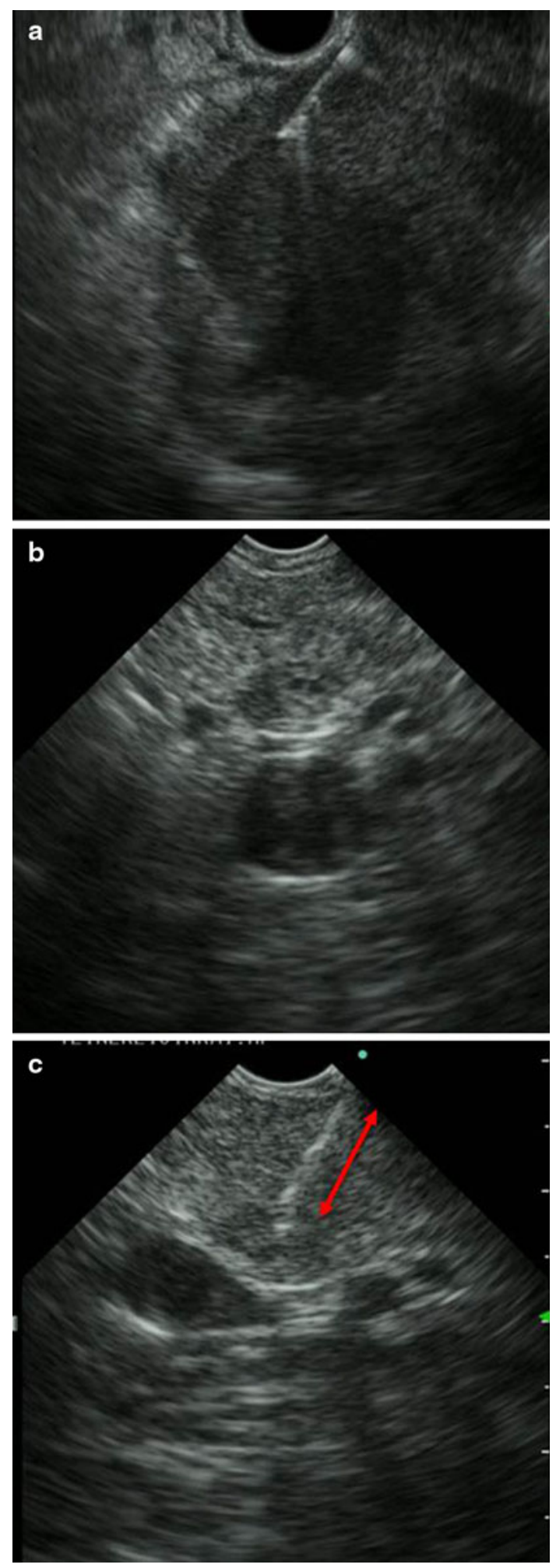

Fig. 1 Using ultrasound images, needle pass site was confirmed as via normal pancreatic tissue. a Needle pass was not via normal pancreas. b Needle pass via normal pancreas. c In cases where the needle pass was via normal pancreatic tissue, the length of the needle penetration was measured. The length was measured using a distance marker on the ultrasonography images and assigned to one of 3 categories: $<1,1-2$, and $>2 \mathrm{~cm}$ test or the Chi square $\left(\chi^{2}\right)$ test for trend. Student's $t$ test was used to compare continuous variables. Multivariate analysis using a logistic regression model was performed using the forward method. The odds ratios (ORs) and $95 \%$ confidence intervals $(95 \% \mathrm{CI})$ were calculated to evaluate the predictors of complications. Two-tailed $P$ values of less than 0.05 were considered statistically significant.

\section{Results}

\section{Adverse Events and Severity Grading After EUS-FNA}

Needle passes were performed for a mean of 2.78 times using 19-, 22-, and 25-G needles for 31 (9.5\%), 268 $(82.0 \%)$, and $28(8.6 \%)$ procedures, respectively (Table 1). The needle pass site was the stomach in 198 cases $(60.6 \%)$ and the duodenum in 129 cases $(39.4 \%)$. The incidence of adverse events was $3.4 \%$ (11 patients): pancreatitis was noted in 6 patients (moderate in 1 case and mild in 5 cases); mild abdominal pain in 4 patients; and mild bleeding in 1 patient (Table 2). The underlying disease was pancreatic cancer in 7 cases, pancreatic neuroendocrine tumor (PNET) in 3 cases, and chronic pancreatitis in 1 case. Eight cases $(73 \%)$ involved small lesions, less than or equal to $20 \mathrm{~mm}$ in diameter. A $19-\mathrm{G}$ needle was used in 2 cases, and a $22-\mathrm{G}$ needle was used in the other 9 cases. Needle passes were performed 2 times in 2 cases, 3 times in 4 cases, 4 times in 3 cases, and 5 times in 2 cases. In 9 cases ( $82 \%$ ), the number of needle passes was 3 or more. The needle pass site was the via normal pancreas in 8 cases $(73 \%$ ) (Table 3$)$. All cases were managed by conservative therapy only.

\section{Risk Factors for Adverse Events}

The following variables were examined in the 327 patients who underwent FNA of the pancreas: age, sex, location of target, tumor size, tumor type (benign, PNET, or other pancreatic tumor), site of needle pass, size of the needle used, mean number of needle passes, whether or not the needle pass was via the normal pancreas, and length of needle penetration into normal pancreas tissue. The results of univariate analysis showed that the incidence of procedural complications was significantly increased in cases

Table 2 Incidence of post-procedure events after EUS-FNA

\begin{tabular}{lll}
\hline & No of cases, \% & Severity grading \\
\hline Pancreatitis & $6,1.8$ & Moderate 1, mild 5 \\
Abdominal pain & $4,1.2$ & Mild 4 \\
Bleeding & $1,0.3$ & Mild 1 \\
Total & $11,3.4$ & Moderate 1, mild 10 \\
\hline
\end{tabular}


Table 3 Characteristics in case of adverse events

\begin{tabular}{|c|c|c|c|c|c|c|c|c|c|c|c|c|}
\hline No. & Age & Sex & Diagnosis & Location & $\begin{array}{l}\text { Size } \\
(\mathrm{mm})\end{array}$ & $\begin{array}{l}\text { Site of } \\
\text { needle } \\
\text { pass }\end{array}$ & $\begin{array}{l}\text { Needle } \\
\text { size } \\
\text { (gauge) }\end{array}$ & $\begin{array}{l}\text { No. of } \\
\text { passes }\end{array}$ & $\begin{array}{l}\text { Presence or } \\
\text { absence of } \\
\text { normal pancreas }\end{array}$ & $\begin{array}{l}\text { Length of the } \\
\text { needle } \\
\text { penetration }\end{array}$ & $\begin{array}{l}\text { Adverse } \\
\text { events }\end{array}$ & Severity \\
\hline 1 & 64 & $\mathrm{~F}$ & $\mathrm{PC}$ & Head & 20 & Duodenum & 22 & 2 & Presence & $1-2 \mathrm{~cm}$ & Pancreatitis & Moderate \\
\hline 2 & 60 & M & PNET & Tail & 26 & Stomach & 19 & 4 & Absence & & Pancreatitis & Mild \\
\hline 3 & 83 & $\mathrm{~F}$ & $\mathrm{PC}$ & Head & 18 & Duodenum & 22 & 3 & Presence & $1-2 \mathrm{~cm}$ & Pancreatitis & Mild \\
\hline 4 & 78 & $\mathrm{~F}$ & PNET & Tail & 8 & Stomach & 22 & 4 & Absence & & Pancreatitis & Mild \\
\hline 5 & 61 & M & $\mathrm{PC}$ & Head & 32 & Duodenum & 22 & 2 & Presence & $<1 \mathrm{~cm}$ & Pancreatitis & Mild \\
\hline 6 & 71 & M & $\mathrm{PC}$ & Head & 20 & Duodenum & 22 & 5 & Presence & $1-2 \mathrm{~cm}$ & Pancreatitis & Mild \\
\hline 7 & 79 & $\mathrm{~F}$ & $\mathrm{PC}$ & Tail & 54 & Stomach & 22 & 4 & Presence & $<1 \mathrm{~cm}$ & Bleeding & Mild \\
\hline 8 & 67 & M & $\mathrm{PC}$ & Head & 15 & Duodenum & 22 & 3 & Absence & & $\begin{array}{l}\text { Abdominal } \\
\text { pain }\end{array}$ & Mild \\
\hline 9 & 75 & M & $\mathrm{CP}$ & Tail & 5 & Stomach & 22 & 3 & Presence & $>2 \mathrm{~cm}$ & $\begin{array}{l}\text { Abdominal } \\
\text { pain }\end{array}$ & Mild \\
\hline 10 & 58 & $\mathrm{~F}$ & $\mathrm{PC}$ & Head & 15 & Duodenum & 19 & 3 & Presence & $<1 \mathrm{~cm}$ & $\begin{array}{l}\text { Abdominal } \\
\text { pain }\end{array}$ & Mild \\
\hline 11 & 85 & M & PNET & Head & 15 & Duodenum & 22 & 5 & Presence & $<1 \mathrm{~cm}$ & $\begin{array}{l}\text { Abdominal } \\
\text { pain }\end{array}$ & Mild \\
\hline
\end{tabular}

$P C$ pancreatic cancer, $P N E T$ pancreas neuroendocrine tumor, $C P$ chronic pancreatitis

involving tumors measuring $\leq 20 \mathrm{~mm}$ in diameter $(P<0.001)$, cases of PNETS $(P=0.012)$, and cases with an increased length of needle penetration (those in which the puncture needle had to traverse normal pancreas tissue) ( $P=0.048)$. Because statistical significance was observed among the 3 disease categories (benign, PNET, and other tumors), we performed paired comparisons. The $P$ values for the paired comparisons were as follows: $P=0.065$ for benign versus PNET, $P=1.000$ for benign versus other tumors, and $P=0.009$ for PNET versus other tumors (Table 4). Multivariate analysis identified tumors measuring less than or equal to $20 \mathrm{~mm}$ in diameter (OR 18.48; $95 \%$ CI 3.55-96.17) and PNETs (OR 36.50; $95 \%$ CI 1.73-771.83) as independent risk factors (Table 5).

\section{Discussion}

In this study, the incidence of post-procedural adverse events was $3.4 \%$, which is slightly higher than that reported in previous studies. However, a prospective study conducted by Sendino et al. [18] reported a complication rate of $3.1 \%$ and a severe complication rate of $1.2 \%$ in 219 patients undergoing EUS-FNA. Although our study was retrospective, a certain level of accuracy was ensured because the patients undergoing FNA were registered in a database and were admitted to the hospital for the procedure. Additionally, the clinical findings, including the results of blood tests performed on the day after EUS-FNA, were recorded precisely. Furthermore, we were able to properly assess not only the patients with severe complications but also those who experienced mild adverse events. Of these 11 cases, all except 1 experienced mild adverse events. Thus, EUS-FNA appears to be a safe procedure for patients with pancreatic solid lesions.

The relationship between the incidence of adverse events after EUS-FNA and needle size is an important issue, and a 22-G needle was our first choice. Siddiqui et al. [19] reported that no adverse events were observed after the procedure using either 22- or 25-G needles. In this study, the results of both univariate and multivariate analyses suggested that needle size was not a factor that was significantly associated with an elevated risk of adverse events. In theory, the incidence of adverse events after EUS-FNA with a larger diameter needle was expected to be higher than that after procedures using needles that were smaller in diameter. Needle pass with a larger diameter needle may increase the risk of both tissue damage and adverse events. However, in our study, moderate pancreatitis occurred in 1 patient with pancreatic cancer when we used a $22-\mathrm{G}$ needle and a needle pass in the duodenum (Fig. 2a). After EUS-FNA, the patient experienced abdominal pain. Abdominal CT revealed fluid collection around the pancreas head (Fig. 2b). We performed a surgery to remove the pancreatic cancer 19 days after EUSFNA. The intraoperative findings revealed a blood clot around the pancreas head lesion, and adhesion was confirmed between the pancreas head and the duodenal wall (Fig. 2c). However, the resection was completely successful.

In this study, univariate analysis revealed the following statistically significant risk factors for post procedural adverse events: tumors measuring less than or equal to $20 \mathrm{~mm}$ in diameter, 3 or more punctures, and a greater 
Table 4 Analysis of risk factors for the complications in patients who underwent FNA of the pancreas

\begin{tabular}{|c|c|c|c|}
\hline & $\begin{array}{l}\text { With } \\
\text { complications } \\
n=11\end{array}$ & $\begin{array}{l}\text { Without } \\
\text { complications } \\
n=316\end{array}$ & $P$ value ${ }^{\mathrm{a}}$ \\
\hline Age & $71.0 \pm 9.6$ & $66.1 \pm 11.4$ & $0.163^{\mathrm{b}}$ \\
\hline \multicolumn{4}{|l|}{ Sex } \\
\hline $\mathrm{M}: \mathrm{F}$ & $7: 4$ & $171: 145$ & 0.760 \\
\hline \multicolumn{4}{|l|}{ Location } \\
\hline Head & 6 & 129 & \multirow[t]{2}{*}{0.371} \\
\hline Body/tail & 5 & 187 & \\
\hline \multicolumn{4}{|l|}{ Tumor size $(\mathrm{mm})$} \\
\hline$\leq 20$ & 3 & 268 & \multirow[t]{2}{*}{$<0.001$} \\
\hline$>20$ & 8 & 48 & \\
\hline Benign & 1 & 34 & \multirow[t]{3}{*}{$0.012^{\mathrm{c}}$} \\
\hline PNETs & 3 & 11 & \\
\hline $\begin{array}{l}\text { Other tumors (PK, } \\
\text { sarcoma, SPN) }\end{array}$ & 7 & 271 & \\
\hline \multicolumn{4}{|l|}{ Site of needle pass } \\
\hline Stomach & 5 & 193 & \multirow[t]{2}{*}{0.353} \\
\hline Duodenum & 6 & 123 & \\
\hline \multicolumn{4}{|l|}{ Needle size (gauge) } \\
\hline 25 & 0 & 28 & \multirow[t]{3}{*}{$0.263^{\mathrm{d}}$} \\
\hline 22 & 9 & 259 & \\
\hline 19 & 2 & 29 & \\
\hline \multicolumn{4}{|c|}{ Number of needle passes } \\
\hline$<2$ & 2 & 156 & \multirow[t]{2}{*}{0.063} \\
\hline$>3$ & 9 & 160 & \\
\hline \multicolumn{4}{|c|}{ Needle pass via the normal pancreas } \\
\hline Yes & 8 & 143 & \multirow[t]{2}{*}{0.121} \\
\hline No & 3 & 173 & \\
\hline \multicolumn{4}{|c|}{ Length of the needle penetration } \\
\hline Absence & 3 & 173 & \multirow[t]{4}{*}{$0.048^{\mathrm{d}}$} \\
\hline$<1 \mathrm{~cm}$ & 4 & 89 & \\
\hline $1-2 \mathrm{~cm}$ & 3 & 43 & \\
\hline$>2 \mathrm{~cm}$ & 1 & 11 & \\
\hline
\end{tabular}

${ }^{\text {a }}$ Fisher's exact test

${ }^{\mathrm{b}} t$ test

c $P$ values for paired comparisons are as follows: $P=0.065$ for benign versus PNETs, $P=1.000$ for benign versus other tumor, and $P=0.009$ for PNETs versus tumor

${ }^{\mathrm{d}}$ Chi-square test for trend

length of penetration in cases where the needle pass had to traverse normal pancreas tissue. Furthermore, in our multivariate analysis, small tumor size and PNETs were found to be significant independent risk factors. One of the potential causes of adverse events may be the difficulty in performing needle passes for small lesions. Needle passes for small tumors may be more difficult to execute than those for large tumor masses. Occasionally, many needle passes are required because the target is too small. In
Table 5 Results of logistic regression on complications after EUSFNA with regard to variables

\begin{tabular}{llr}
\hline Factor & OR $(95 \% \mathrm{CI})$ & $P$ value \\
\hline Sex $(\mathrm{M})$ & $1.87(0.40-8.70)$ & 0.424 \\
Age & $1.07(0.99-1.16)$ & 0.088 \\
Tumor location (body/tail) & $0.71(0.02-21.35)$ & 0.845 \\
Tumor size $(\leqq 20 \mathrm{~mm})$ & $18.48(3.55-96.17)$ & $<0.001$ \\
Benign & Ref. & \\
PNETs & $36.50(1.73-771.83)$ & 0.021 \\
Other tumor & $6.76(0.47-96.38)$ & 0.159 \\
Site of needle pass (Duodenum) & $1.77(0.06-53.06)$ & 0.742 \\
Needle size (22/25-gauge) & $0.20(0.03-1.63)$ & 0.134 \\
Number of needle passes $(>3$ time & $3.56(0.56-22.50)$ & 0.178 \\
Length of the needle penetration & & \\
Absence & Ref. & \\
$<1 \mathrm{~cm}$ & $1.49(0.24-9.43)$ & 0.669 \\
$1-2 \mathrm{~cm}$ & $3.20(0.44-23.02)$ & 0.249 \\
$<2 \mathrm{~cm}$ & $9.71(0.63-148.57)$ & 0.103 \\
\hline
\end{tabular}

addition, back-and-forth movement is difficult. This may lead to pancreatic damage and adverse effects such as pancreatitis and bleeding. Moreover, the possible causes of pancreatitis include injuries to the main pancreatic duct or its branches. Although penetration through the normal pancreas was not found to be a risk factor in our multivariate analysis, a needle pass through the normal pancreas was more likely to be necessary for accessing small lesions, and the possibility of injuries to the normal pancreas and the main pancreatic duct or its branches cannot be ignored. Vascularity of the target lesion is another factor. Our data demonstrate that PNETs are a risk factor for adverse events. In general, PNETs are hypervascular tumors and the risk of bleeding from these tumors is increased compared with other tumors. When bleeding occurs around the pancreatic parenchyma after EUS-FNA, it may cause inflammation and lead to adverse events. These factors may have helped identify a small tumor size and PNETs as risk factors. Because this was a retrospective study, a prospective study involving a larger number of patients is needed to precisely determine the risk of adverse events.

The limitations of this study included the fact that it was a retrospective analysis performed at a single center, and only pancreatic solid lesions were included. Cystic lesions of the pancreas, especially intraductal papillary neoplasms (IPMN), are contraindications for EUS-FNA not only in our center but also in many other Japanese institutions because of the risk of tumor dissemination due to leakage of cystic fluid. For this reason, we could only evaluate pancreatic solid lesions. The frequency of complications associated with pancreatic solid lesions after EUS-FNA is low compared with that associated with cystic lesions [12, 

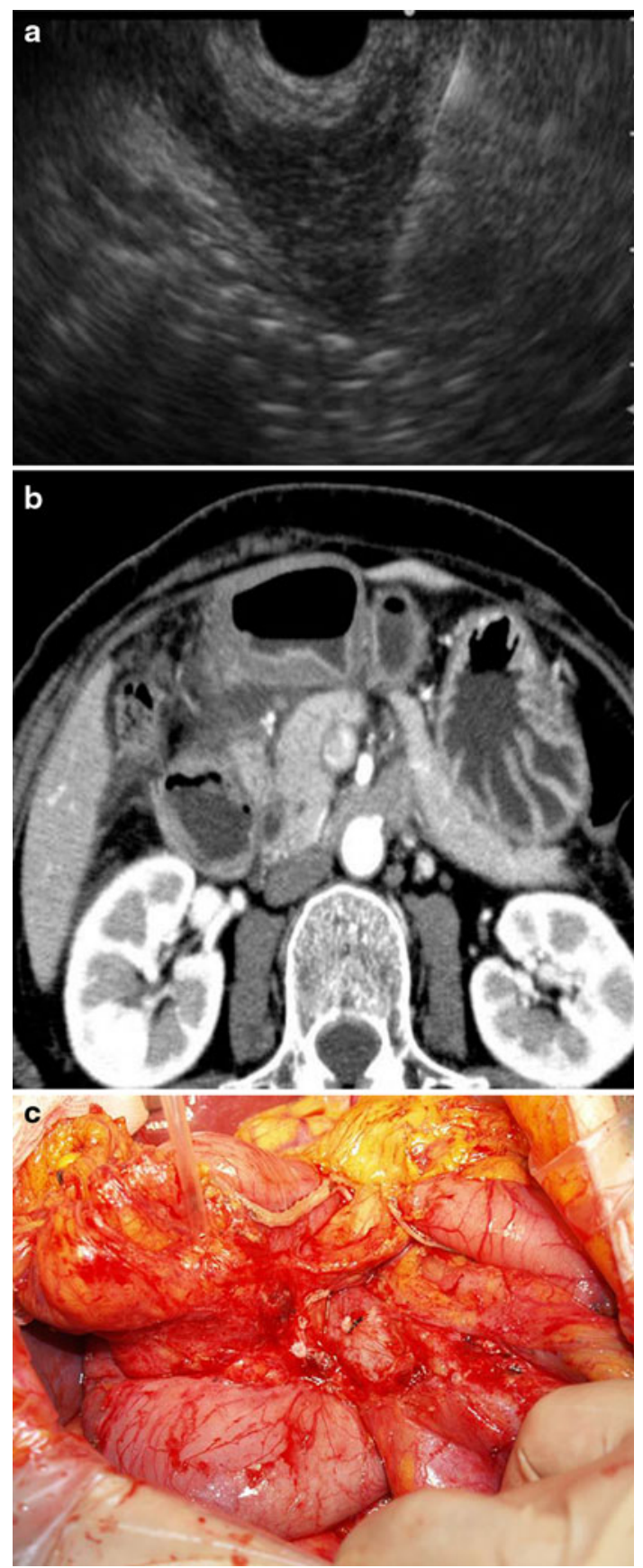

Fig. 2 A case of pancreatitis after EUS-FNA. a FNA was performed using 22-gauge needle. b Abdominal CT revealed fluid collection around the pancreas head. c The intraoperative findings revealed a blood clot around the pancreas head lesion, and adhesion was confirmed between the pancreas head and the duodenal wall

20]. However, in our study, the rate of complications was $3.4 \%$, including mild cases. The possible mechanisms for the development of adverse events differ depending on whether the lesion is solid or cystic. Therefore, determining the risk factors for adverse events after EUS-FNA in patients with pancreatic solid lesions is very important. Moreover, owing to improvements in echoendoscope and needles, we can now visualize smaller lesions and attempt to perform EUS-FNA of these lesions. For these reasons, a clarification of the risk factors associated with EUS-FNA is necessary.

In conclusion, EUS-FNA of pancreatic solid lesions is a safe procedure. However, pancreatic lesions with small diameters and PNETs are important factors associated with adverse events following EUS-FNA.

\section{Conflict of interest None.}

Open Access This article is distributed under the terms of the Creative Commons Attribution Noncommercial License which permits any noncommercial use, distribution, and reproduction in any medium, provided the original author(s) and the source are credited.

\section{References}

1. Vilmann P, Jacobson GK, Henriksen FW, et al. Endoscopic ultrasonography with guided fine needle aspiration biopsy in pancreatic disease. Gastrointest Endosc. 1992;38:172-173.

2. Eloubeidi MA, Chen VK, Eltoum IA, et al. Endoscopic ultrasound-guided fine needle aspiration biopsy of patients with suspected pancreatic cancer: diagnostic accuracy and acute and 30-day complications. Am J Gastroenterol. 2003;98:2663-2668.

3. Gress F, Gottlieb K, Sherman S, et al. Endoscopic ultrasonographyguided fine-needle aspiration biopsy of suspected pancreatic cancer. Ann Intern Med. 2001;134:459-464.

4. Harewood GC, Wiersema MJ. Endosonography-guided fine needle aspiration biopsy in the evaluation of pancreatic masses. Am J Gastroenterol. 2002;97:1386-1391.

5. Savides TJ, Donohue M, Hunt G, et al. EUS-guided FNA diagnostic yield of malignancy in solid pancreatic masses: a benchmark for quality performance measurement. Gastrointest Endosc. 2007;66:277-282.

6. Hoda KM, Rodriguez SA, Faigel DO. EUS-guided sampling of suspected GI stromal tumors. Gastrointest Endosc. 2009;69:1218-1223.

7. Mekky MA, Yamao K, Sawaki A, et al. Diagnostic utility of EUS-guided FNA in patients with gastric submucosal tumors. Gastrointest Endosc. 2010;71:913-919.

8. Philipper M, Hollerbach S, Gabbert HE, et al. Prospective comparison of endoscopic ultrasound-guided fine needle aspiration and surgical histology in upper gastrointestinal submucosal tumors. Endoscopy. 2010;42:300-305.

9. Yasuda I, Tsurumi H, Omar S, et al. Endoscopic ultrasoundguided fine needle aspiration biopsy for lymphadenopathy of unknown origin. Endoscopy. 2006;38:919-924.

10. Krishna NB, Gardner L, Collins BT, et al. Periportal lymphadenopathy in patients without identifiable pancreatobiliary or hepatic malignancy. Clin Gastroenterol Hepatol. 2006;4:1373-1377.

11. O'Toole D, Plazzo L, Arotçarena R, et al. Assessment of complications of EUS-guided fine-needle aspiration. Gastrointest Endosc. 2001;53:470-474.

12. Mortensen MB, Fristrup C, Holem FS, et al. Prospective evaluation of patients tolerability, satisfaction with patient information, and complications in endoscopic ultrasonography. Endoscopy. 2005;37:146-153.

13. Lee LS, Saltzman JR, Bounds BC, et al. EUS-guided fine needle aspiration of pancreatic cysts: a retrospective analysis of complications and their predictors. Clinical Gastroenterol and Hepatol. 2005;3:231-236. 
14. Al-Haddad M, Wallace MB, Woodward TA, et al. The safety of fine-needle aspiration guided by endoscopic ultrasound: a prospective study. Endoscopy. 2008;40:204-208.

15. Eloubeidi MA, Tamhane A. Prospective assessment of diagnostic utility and complications of endoscopic ultrasound-guided fine needle aspiration. Results from a newly developed academic endoscopic ultrasound program. Dig Dis. 2008;26:356-363.

16. Fabbri C, Luigiano C, Cennamo V, et al. Complications of endoscopic ultrasonography. Minerva Gastroentero Dietol. 2011; 57:159-166.

17. Cotton PB, Eisen GM, Aabakken L, et al. A lexicon for endoscopic adverse events: report of an ASGE workshop. Gastrointest Endosc. 2010;71:446-454.
18. Sendino O, Garcia P, Gimeno-Garcia AZ, et al. Complications of endoscopic ultrasonography (EUS) and EUS-guided fine needle aspiration (EUS-FNA): a prospective investigation in a large series of patients. Gastrointest Endosc. 2007; 65:AB199.

19. Siddiqui UD, Rossi F, Rosenthal LS, et al. EUS-guided FNA of solid pancreatic masses: a prospective, randomized trial comparing 22-gauge and 25-gauge needles. Gastrointest Endosc. 2009;70:1093-1097.

20. Bournet B, Migueres I, Delacroix M, et al. Early morbidity of endoscopic ultrasound: 13 years' experience at a referral center. Endoscopy. 2006;38:349-354. 